\title{
Comparison of changes in vegetation and land cover types between Shenzhen and Bangkok
}

\author{
Yi Song ${ }^{1,2}$, Jagannath Aryal ${ }^{3,4}$, Liangcheng Tan ${ }^{1,2,5}$, Long Jin ${ }^{6}$, Zhihua Gao ${ }^{7}$ and Yunqiang Wang ${ }^{1,2}$ \\ 1 State Key Laboratory of Loess and Quaternary Geology, Institute of Earth Environment, Chinese Academy of Sciences, \\ Xi'an 710061, China \\ 2 CAS Center for Excellence in Quaternary Science and Global Change, Xi’an, 710061, China \\ 3 Discipline of Geography and Spatial Sciences, University of Tasmania, Hobart, 7001, Australia \\ 4 Melbourne School of Engineering, Department of Infrastructure Engineering, The University of Melbourne, Parkville, \\ Victoria 3010, Australia \\ 5 Institute of Global Environmental Change, Xi'an Jiaotong University, Xi'an 710054, China \\ 6 College of Civil Engineering, Xi'an University of Science and Technology, Xi'an 710065, China \\ 7 School of Civil Engineering, Chang'an University, Xi’an 710064, China
}

\begin{abstract}
Corresponding authors: Yi Song, songyi@ieecas.cn
Running title: Changes in vegetation and land cover types of two Asian cities
\end{abstract}

Acknowledgments: This research was funded by the Strategic Priority Research Program of the Chinese Academy of Sciences (No. XDB40020203), the Youth Innovation Promotion Association of the Chinese Academy of Sciences (No. 2018446), the Shaanxi Science Fund for Distinguished Young Scholars (No. 2018JC-023) and the New Star Project of Youth Science and Technology of Shaanxi Province in China (No. 2016KJXX-91). This work is part of the "Belt \& Road" project of the Institute of Earth Environment, Chinese Academy of Sciences.

\section{Data Availability Statement:}

The MODIS MCD12Q1 and MOD13Q1 datasets were obtained from the Land Processes Distributed Active Archive Center (LPDAAC) of NASA (https://lpdaac.usgs.gov/). The CCI-LC dataset was obtained from the European Space Agency (ESA) (https://www.esa-landcovercci.org/). The meteorological data for Shenzhen were obtained from the National Meteorological Information Center of the China Meteorological Administration (http://data.cma.cn/). The

This is the author manuscript accepted for publication and has undergone full peer review but has not been through the copyediting, typesetting, pagination and proofreading process, which may lead to differences between this version and the Version of Record. Please cite this article as doi: $10.1002 / \mathrm{ldr} .3788$

This article is protected by copyright. All rights reserved. 
meteorological data of Bangkok were obtained from the Thai Meteorological Department Automatic Weather System (http://www.aws-observation.tmd.go.th/).

This article is protected by copyright. All rights reserved. 


\begin{abstract}
As important node cities in the Belt and Road region, Shenzhen and Bangkok are faced with similar environmental threats posed by the high-speed social development process. Rapid urbanization leads to changes in vegetation growth and land cover types and then affects ecosystem services. In the current study, we used a time-series normalized difference vegetation index dataset from 2000 to 2019 and two land cover type datasets from 2000 to 2018 to investigate and compare the spatiotemporal characteristics of the changes in vegetation and land cover types of the two cities. We found that the trend of vegetation change was mainly affected by the change in land cover types, while the interannual fluctuation of vegetation change was likely related to the extreme climate events caused by El NiñoSouthern Oscillation events. However, different urbanization strategies led to opposite vegetation change trends in Bangkok and Shenzhen after 2005. With urbanization, the vegetation coverage $\left(P_{v}\right)$ of Shenzhen increased from $48 \%$ in 2000 to $62 \%$ in 2018. The total urban green spaces (except croplands) of Shenzhen have remained above $33 \%$ of the total area since 2006. However, the total urban green space in Bangkok accounted for only $8 \%$ of the total area in 2018 , which was even lower than the area percentage of Shenzhen's forests in the same year. Rapid urbanization without adequate urban green spaces caused a decreasing trend of $P_{v}$ in Bangkok. Green development under the Belt and Road Initiative requires serious considerations of environmental quality and urban livability during the rapid urbanization.
\end{abstract}

Keywords: Belt and Road region; urban vegetation change; land cover dynamics; Asian summer monsoon; urban sustainability

\title{
1. Introduction
}

Monitoring changes in vegetation growth and understanding their causes are key issues influencing global changes that affect terrestrial ecosystems (Fu et al., 2010; Kelly, Tuxen, \& Stralberg, 2011; Piao et al., 2011). Urbanization is likely to have significant impacts on ecosystem services and functions (T. Li, Li, \& Qian, 2010). Observing changes in vegetation and land cover types in urban areas can provide key information for the assessment of urban ecosystem services and landscape sustainability (Y. Liu, Zhao, Hua, Wang, \& Fu, 2019). In 2013, China launched an ambitious foreign policy initiative named the Belt and Road Initiative (BRI) along the ancient Silk 
Road that will greatly influence the future of global trade, particularly in Asia, Africa and Europe (Ascensão et al., 2018). Most countries in the Belt and Road (BR) region are developing countries with rapid urbanization, high rural poverty rates and serious environmental threats (Y. Liu et al., 2019). Some scientists anticipated an increasing tendency of urbanization dependency in space, imposing greater pressures on urban landscapes and ecosystems in the BR region (H. Liu et al., 2018). The spatiotemporal changes in vegetation greening and land cover types of the $B R$ region were dramatic (Lechner, Chan, \& Campos-Arceiz, 2018). Liu et al., revealed that slower vegetation greening (or turn to browning) in the BR region corresponding to faster social developments (Y. Liu et al., 2019). The changes in vegetation and land cover types that were influenced by human management are likely to become an increasingly important issue in the urban areas of the BR region.

In order to clarify the effect of human management on urban environment, we selected two Asian metropolitan cities, Shenzhen and Bangkok, which adopted different urbanization strategies in the BR region as our study area. Shenzhen Municipality was established in November 1979. In its second year, it became a provincial-level economic administration, i.e., the Special Economic Zone. In the more than 40 years since China's reform and opening-up policy, Shenzhen has evolved from a small town to one of the economic centers of China. The resident population of Shenzhen increased from 0.3 million in 1980 to 10.62 million in 2014, with a population density of approximately 10 thousand per square kilometer (Hong \& Guo, 2017). Recognizing the considerable environmental degradation caused by high-speed social development, the Chinese government has adopted a series of regulations and policies to increase the area of public green spaces in urban cities in the last 20 years (W. Y. Chen \& Hu, 2015; Zhao et al., 2013). Moreover, Shenzhen demarcated the first eco-control line of China and implemented urban green belt systems in 2005. As the capital city and the only metropolitan city of Thailand, Bangkok is experiencing rapid urbanization and is faced with considerable population pressure and other environmental challenges (Ali, Pumijumnong, \& Cui, 2018). The population of Bangkok increased from 4.7 million in 1980 to more than 10 million in 2016 (Permpool, Bonnet, \& Gheewala, 2016). The 
environmental threats that Bangkok faces are similar to those that Shenzhen has encountered before and is experiencing now. Although the two cities are affected by different the climate conditions, they have experienced rapid population growth and urban sprawl, both of which have transformed the regional natural landscape. We can still get many key information for the assessment of urban ecosystem services and landscape sustainability through comparing the trends of vegetation change induced by different urbanization strategies between the two cities. The objectives of this study were to (1) investigate the spatiotemporal characteristics of the changes in vegetation and land cover types of the two important node cities in the BR region after 2000; (2) reveal the vegetation response to extreme climate events in the Asian monsoon region; and (3) compare and assess the impacts of different strategies of land management on the urban environment between the two cities.

\section{Materials and Methods}

\subsection{Study area}

Bangkok and Shenzhen are two important node cities in the BR region. The climate of two cities is controlled by the Asian monsoon system. Bangkok is the capital city of Thailand. It is located in the south of the Indochina Peninsula and on the central plain of the Chao Phraya River $\left(100^{\circ} 33^{\prime}-100^{\circ} 94^{\prime} \mathrm{E}, 13^{\circ} 49^{\prime}-13^{\circ} 96^{\prime} \mathrm{N}\right)$, and the city has 50 administrative districts (Supplementary Figure S1a). It is influenced by the Indian monsoon climate, with an average annual temperature of $28.5^{\circ} \mathrm{C}$ and an annual precipitation of $1542 \mathrm{~mm}$. The average precipitation is more than $150 \mathrm{~mm}$ per month in the rainy season (during May to Oct.) and less than $70 \mathrm{~mm}$ per month in the dry season (during Nov. to Apr.). The hot dry season lasts approximately 6 months.

Shenzhen is a coastal city in the south of Guangdong Province, China. It is located to the east of the Pearl River, north of Hong Kong and south of Dongguan and Huiyang $\left(113^{\circ} 43^{\prime}-114^{\circ} 38^{\prime} \mathrm{E}\right.$, $\left.22^{\circ} 24^{\prime}-22^{\circ} 52^{\prime} \mathrm{N}\right)$. It has eight administrative districts, including Bao’an, Nanshan, Longhua, Futian, Luohu, Yantian, Longgang, and Pingshan, and two functional districts, including Guangming and Dapeng (Supplementary Figure S1b). The city is influenced by the East Asian 
monsoon climate, with an average annual temperature of $22.7^{\circ} \mathrm{C}$ and an annual precipitation of $1944 \mathrm{~mm}$. The names of the administrative districts and the near regions of the two cities in the following analysis and discussion can be found in the Supplementary Figure S1.

\subsection{Data and data processing}

In the current study, two yearly land cover type datasets, MODIS MCD12Q1 from 2001 to 2018 and the climate change initiative land cover (CCI-LC) product from 2000 to 2018, were used to analyze the dynamics of the land cover types. The MCD12Q1 dataset contains 5 different classification systems (Friedl et al., 2010; Ganguly, Friedl, Tan, Zhang, \& Verma, 2010); however, our study only focused on the International Geosphere Biosphere Programme (IGBP) system. The CCI-LC dataset was produced based on the United Nations Land Cover Classification System (UN-LCCS). The MODIS MCD12Q1 dataset has a spatial resolution of $500 \mathrm{~m}$, and the CCI-LC dataset has a spatial resolution of $300 \mathrm{~m}$. The Moderate Resolution Imaging Spectroradiometer (MODIS) normalized difference vegetation index (NDVI) dataset from 2000 to 2019 was used to analyze the vegetation change of the two cities. The MODIS NDVI dataset (MOD13Q1) has a temporal resolution of 16 days and a spatial resolution of $250 \mathrm{~m}$.

The NDVI is expressed over a range from -1 to +1 . The NDVI ranges between -0.2 and 0.1 for snow, inland water bodies, deserts, and bare soils. The NDVI increases from 0.1 to 1.0 as the level of vegetation greenness increases. The maximal NDVI (MNDVI) during the whole year was calculated to represent the best state of vegetation growth in that year. The seasonal integrated NDVI (SINDVI) was defined as the cumulative value of the NDVIs that exceeded 0.1 for each pixel during a whole year. The annual NDVI is important in the trend analysis of vegetation change. Compared to the MNDVI, the SINDVI can enhance the annual variability in the NDVI time series (Song, Jin, \& Wang, 2018). Thus, the SINDVI was used in the trend analysis (Subsection 2.2) and the abrupt test (Subsection 2.3). However, vegetation coverage $\left(P_{v}\right)$ should be calculated using the NDVI but not an integrated value. Thus, we used the MNDVI to calculate the yearly vegetation coverage $\left(P_{v}\right)$. 
The annual averaged temperature (AT) and annual precipitation (P) of Shenzhen and Bangkok were used in the current study. We collected the meteorological data for both Shenzhen (from 2000 to 2018) and Bangkok (from 2007 to 2019). However, the meteorological data for Bangkok before 2007 were not available.

\subsection{Trend analyses for vegetation change}

The greenness rate of change (GRC) (Stow et al., 2003) was used to quantify the vegetation change trend. The GRC was defined as the slope of the line that provided the best fit to the SINDVI values over the entire time period of the current study ( $n=20$ years). The $G R C$ was fitted using the least squares method as follows:

$$
G R C=\frac{n \times \sum_{i=1}^{n} i \times \operatorname{SINDVI}_{i}-\sum_{i=1}^{n} i \sum_{i=1}^{n} \operatorname{SINDVI}_{i}}{n \times \sum_{i=1}^{n} i^{2}-\left(\sum_{i=1}^{n} i\right)^{2}},
$$

where $S I N D V I_{i}$ is the SINDVI value for the $i$ th year. The range of the change in SINDVI time series can be calculated as the product of the $G R C$ and $n-1$ years.

The significance of the SINDVI change was assessed using the Mann-Kendall (MK) test, which is a non-parametric statistical test that is widely used to detect trends in hydrological, climatic and environmental factors (Sicard, Mangin, Hebel, \& Malléa, 2010; Zhang, He, Burnham, \& Zhang, 2016). The confidence level of $\alpha$ was set to 0.05 in the current study.

We also calculated the yearly $P_{v}$ using the MNDVI as follows (Carlson \& Ripley, 1997):

$$
P_{v}=\left(\frac{M N D V I-N D V I_{\min }}{N D V I_{\max }-N D V I_{\min }}\right)^{2},
$$

where the $N D V I_{\min }$ and $N D V I_{\max }$ values were 0.1 and 0.8 , respectively.

\subsection{Abrupt test}

In the current study, we used the Pettitt test (Pettitt, 1979) to identify the abrupt changes that occurred in the time series of SINDVI (x1, x2, .., xn). The statistic $k$ of the Pettitt test at time $\tau$ can be expressed as follows:

$$
k_{\tau}=\sum_{i=1}^{\tau} \sum_{j=1}^{n} \operatorname{sgn}\left(x_{i}-x_{j}\right) .
$$


The point of abrupt change most likely occurs at the time when the absolute value of $k_{\tau}$ reaches its maximum value. Thus, the Pettitt test can identify only one abrupt point in a time series. If a time series has more than one significant abrupt point, this algorithm identifies only the largest abrupt point, and it will ignore others, even if they are also significant. According to the results of the trend analysis, vegetation change during the entire study period can be divided into two stages: the stage of fluctuation in the first 10 years and the stage of increase (or decrease) in the second 10 years. Thus, we divided the entire time period of the current study (2000 to 2019) into two time subseries with a 2-year overlap (2000-2010 and 2009-2019) since the end of the year in the time series cannot be detected as an abrupt point. The significance of the abrupt change was approximated by:

$$
p \approx 2 \times \exp \left(\frac{-6 K^{2}}{n^{3}+n^{2}}\right)
$$

The significance level was set to 0.05 .

\section{Results}

\subsection{Land cover dynamics in Bangkok and Shenzhen}

\section{Comparison of the two land cover datasets}

We calculated the area percentage of each land cover type for Bangkok and Shenzhen in 2018 using the MCD12Q1 dataset and the CCI-LC dataset, respectively (Figure 1). For both Bangkok and Shenzhen, the percentage of urban areas and savannas in the MCD12Q1 dataset was higher than that in the CCI-LC dataset (the classification system of the CCI-LC dataset is different from that of the MCD12Q1 dataset; the shrub or herbaceous cover in the CCI-LC dataset corresponds to savanna in the MCD12Q1 dataset). In particular, the area percentage of urban areas in Bangkok (62.4\% of the total area) in the MCD12Q1 dataset was 12.7\% higher than that in the CCI-LC dataset. However, the percentage of croplands in the MCD12Q1 dataset was lower than that in the CCI-LC dataset. In Bangkok, the area percentage of croplands in the MCD12Q1 dataset (4.3\% of the total area) was 33\% lower than that in the CCI-LC dataset. In Shenzhen, the area percentage 
of croplands in the MCD12Q1 dataset (0.7\%) was 18.2\% lower than that in the CCI-LC dataset. The results indicate that the two land cover datasets have large differences in terms of not only the special resolution and classification systems but also the accuracy.

\section{Insert Figure 1}

We used an image of a small region in Shenzhen $(12.8 \times 5.7 \mathrm{~km}$ area in Longgang district), which was collected on August 2 ${ }^{\text {nd }}$, 2018, from Google Earth to access the accuracy of the two land cover datasets. The MCD12Q1 dataset had higher commission errors than the CCI-LC dataset. More non-urban areas were classified as urban area by mistake in the MCD12Q1 dataset compared to the CCI-LC dataset (Figure 2). The misclassification of non-urban areas is the main reason for the higher proportion of urban area in the MCD12Q1 dataset. Thus, the results calculated using the CCI-LC dataset are more reliable for the analysis of land cover dynamics caused by urbanization.

\section{Insert Figure 2}

\section{Area change of different land cover types in Bangkok and Shenzhen}

We calculated the area difference of each land cover type between 2018 and 2000 using the CCI-LC dataset for the two cities (Figure 3a). The area of forests in Shenzhen increased by more than $50 \mathrm{~km}^{2}$, accounting for 3\% of the city area and 14\% of the total forest area in 2018 . The percentage of forests in Shenzhen has exceeded 20\% of the total area since 2010. The area of urban regions in Shenzhen increased by $377 \mathrm{~km}^{2}$. The increased area of urban regions in Shenzhen accounted for $20 \%$ of the total area and $45 \%$ of the total area of urban regions in 2018 . The new forests and urban regions mainly came from croplands and grasslands. The decreases in the area of croplands and grasslands accounted for $38 \%$ and $87 \%$ of the total area of croplands and grasslands in 2000, respectively. The area of urban regions grew rapidly before 2005, and exceeded that of croplands in 2001. Then the rate of urbanization slowed, and the percentage of cropland remained stable (accounting for approximately $20 \%$ of the total area) for the last 10 years. In 
Bangkok, the area of croplands and urban regions varied greatly from 2000 to 2018 (Figure 3b). Nearly $320 \mathrm{~km}^{2}$ of croplands in Bangkok, accounting for $20 \%$ of the city area, shifted to urban regions from 2000 to 2018. The area of urban regions exceeded that of croplands in 2012. The mean rate of urbanization was $20.5 \mathrm{~km}^{2}$ per year. Other non-urban regions, including urban green spaces (except croplands) and water bodies, decreased by $50 \mathrm{~km}^{2}$ during the 19 years. The area of these non-urban regions (except croplands) accounted for 13\% of the total Bangkok area in 2018, which was even less than the percentage of forests in Shenzhen. The total percentage of urban green spaces (except croplands) and water bodies in Shenzhen reached 37\% in 2018.

\section{Insert Figure 3}

\section{Spatial characteristics of land cover dynamics in Bangkok and Shenzhen}

In Bangkok, $610 \mathrm{~km}^{2}$ of croplands (320 km² of which was in the city of Bangkok, and 290 $\mathrm{km}^{2}$ was in Nonthaburin Province and Samut Prakan Province) shifted into urban regions (Figure 4a). Over $90 \%$ of new urban regions in Bangkok came from croplands. However, urban green spaces such as forests and grass did not increase. In Shenzhen, the new urban regions accompanied by some new forests are mainly located around the northern areas bordering the cities of Dongguan and Huiyang. More new forests were mainly distributed in the Dapeng district and the three national forest parks in the districts of Bao'an and Nanshan, which are in western Shenzhen (Figure 4b). Approximately $13 \%$ of the new forests ( $53 \mathrm{~km}^{2}$ in total) came from croplands, $25 \%$ came from mosaic cropland and nature vegetation and the other $62 \%$ came from shrub and herbaceous cover. The Shenzhen government implemented urban green belt systems in 2005 to increase urban green spaces. Moreover, a three-level park system, which enables citizens to reach parks within 500 meters, was also established. The Shenzhen government has built many new parks and renovated existing ones every year. The increasing area of urban green spaces has continuously promoted urban greening in Shenzhen.

Insert Figure 4 


\subsection{Vegetation change in Bangkok and Shenzhen}

Opposite vegetation change trends in Bangkok and Shenzhen since 2006

In the 20-year period (from 2000 to 2019), over half of the Shenzhen area was found to have a significant increase in the SINDVI at a confidence level $(\alpha)$ of 0.05 (Figure 5, Table 1); increases were especially high in the districts of Bao'an, Nanshan, Longhua and Futian, which are in the west of Shenzhen. Three national forest parks and several smaller botanical parks are located in those areas. This result indicated that the vegetation in the parks near the urban regions of Shenzhen improved during this 20-year period. Significant SINDVI increase also appeared in the Dapeng district, because the land cover types there had shifted into forests (Figure 4b). Only in a few urban regions did vegetation decrease significantly, which mainly caused by the urban sprawl. In Bangkok, the area where vegetation decreased significantly was 2.1 times larger than the area where vegetation increased significantly. The regions where vegetation decreased were distributed from the downtown area to the nearby regions. These areas with significant SINDVI decrease matched the areas which changed from croplands or shrub to urban regions (Figure 4a). Moreover, the vegetation in Nonthaburi Province and Samut Prakan Province, which are located to the northwest and southeast of Bangkok, respectively, decreased more than the vegetation within Bangkok.

\section{Insert Figure 5}

\section{Insert Table 1}

The $P_{v}$ of Bangkok showed lower spatial heterogeneity than that of Shenzhen (Figure 6). Savannas and croplands are the main vegetation types in Bangkok. The $P_{v}$ decreased in the downtown and nearby regions of Bangkok. Moreover, the $P_{v}$ of Nonthaburi and Samut Prakan decreased even more than that of Bangkok (Figure 6b). In Shenzhen, forest (including evergreen needleleaf, broadleaf and mixed forests) and savannas were the main vegetation types. Before 2006, regions with a higher $P_{v}$ were mainly distributed in the district of Dapeng, which is located 
on the peninsula east of Mirs Bay (Figure 6c). Then, the vegetation in the three national forest parks and several smaller botanical parks in central and western Shenzhen improved significantly (Figure 6d). The $P_{v}$ of those parks increased greatly due to the implementation of the vegetation regreening and restoration project and the protection of water conservation forest and the urban ecological environment (more details are provided in the subsection on land cover dynamics). The $P_{v}$ values of the two cities were at the same level before 2006, and then they shifted into opposite trends (Figure 6e).

\section{Insert Figure 6}

Abrupt points in Bangkok and Shenzhen from 2000 to 2019

During the first time subseries of 2000-2010, significant troughs $(\alpha=0.05)$ occurred in 2004 in both Bangkok and Shenzhen (Figure 7). This result is consistent with that shown in Figure 6e. The regions with significant troughs in 2004 matched the regions with significant SINDVI decrease due to urban sprawl in both Bangkok and Shenzhen. The significant peaks $(\alpha=0.05)$ mostly occurred in 2005 in Shenzhen, accounting for 10\% of its area. However, only less than 1\% of the area of Bangkok showed significant peaks in the district of Bang Khun Thian, which is in the southwest section of Bangkok. During the second time subseries of 2009-2019, however, almost no significant peaks or troughs were found in the two cities.

\section{Insert Figure 7}

Shenzhen and Bangkok have experienced rapid urbanization with dramatic dynamics in land cover types. However, the $P_{v}$ of the two cities changed in opposite trends after 2005. According to Figure 5 and 6, the regions where $P_{v}$ decreased in Bangkok were the areas where croplands shifted into urban regions. The loss of farmland and the lack of urban green spaces caused by rapid urbanization were the main reason for the decline in the $P_{v}$ value of Bangkok after 2005. In Shenzhen, however, $P_{v}$ increased due to the greening and improvement for the existing urban green 
spaces. These results indicate that the different urbanization strategy adopted by Bangkok and Shenzhen led to the opposite trends in $P_{v}$ of the two cities after 2005.

\section{3 climate fluctuation and vegetation change}

The climate in East and Southeast Asia is controlled by the Asian monsoon system, i.e., the East Asian monsoon and the Indian monsoon, which is strongly influenced by El Niño-Southern Oscillation (ENSO) events (Tan et al., 2019). This global climate phenomenon recurs irregularly every 2 to 7 years, causing periodic extremes in the regional climate. Sudden changes in the vegetation index always occur in the years of El Niño (warm year) and La Niña (cool year) (Suepa, Qi, Lawawirojwong, \& Messina, 2016). Our results showed that the troughs in the SINDVI series mostly occurred in La Niña years (Figure 8). The relative intensities of past El Niño and La Niña events were classified based on the Oceanic Niño Index using the ERSSTv5 data (Huang et al., 2017). In Bangkok, 3 troughs occurred in 2000 (weak La Niña year), 2008 (strong La Niña year) and 2012 (moderate La Niña year). In Shenzhen, 4 troughs occurred in 2000, 2008, 2011 (strong La Niña year) and 2017 (weak La Niña year). Peaks always occurred in El Niño years, such as the peaks of Bangkok in 2010 (moderate El Niño year) and 2016 (strong El Niño year) and the peaks of Shenzhen in 2010 and 2015 (weak El Niño year). However, the abrupt changes in the SINDVI series mostly matched the troughs or peaks of the P in Bangkok and the troughs or peaks of the AT in Shenzhen. This result indicated that the fluctuations of vegetation were closely related to the climate fluctuation caused by the ENSO events in the two cities. The climate factor to which vegetation is more sensitive plays a leading role in vegetation growth. Rainy summers and dry winters are common features of the two cities. However, Bangkok is hotter and Shenzhen is wetter. Higher temperatures cause more evapotranspiration; thus, vegetation growth consumed more water in Bangkok. In contrast, the vegetation in Shenzhen consumes less water than that in Bangkok. Consequently, the minimum precipitation threshold required for vegetation growth in Bangkok is higher than that in Shenzhen. If $\mathrm{P}$ is under the minimum precipitation threshold, vegetation growth will be mainly affected by water stress. In that case, $\mathrm{P}$ will play a leading role 
in vegetation growth, as in Bangkok. If $\mathrm{P}$ is above the threshold, in most cases, $\mathrm{P}$ will no longer be the dominant factor affecting plant growth, and AT will instead play the leading role in vegetation change, as was observed in Shenzhen. Moreover, we found that the $P_{v}$ troughs of Shenzhen in 2004 and 2011 matched the troughs of P in the same years. These two years had the lowest P values (less than $1300 \mathrm{~mm}$ ) from 2000 to 2018. However, in 2015, $P_{v}$ reached a peak value because the AT reached a peak value, although $\mathrm{P}$ was only $1501 \mathrm{~mm}$, which was the third lowest precipitation in the 19-year period. This result indicated that $1501 \mathrm{~mm}$ exceeded the minimum precipitation threshold for vegetation growth in Shenzhen, but the value of $1300 \mathrm{~mm}$ did not. Thus, the minimum precipitation threshold for vegetation growth in Shenzhen is approximately 1400 mm (the blue dashed line in Figure 8b). For Bangkok, we found that $P_{v}$ reached a peak value when the AT reached a peak value in 2010, although P was $2069 \mathrm{~mm}$ and did not reach its peak value in the same year. In the next year, P increased to $2353 \mathrm{~mm}$, but $P_{v}$ decreased as the AT decreased. In 2013, P was $1799 \mathrm{~mm}$, which was less than that in 2010. However, $P_{v}$ was at a peak value that matched the peak of $\mathrm{P}$ in the same years. This result indicated that the precipitation amount of $2069 \mathrm{~mm}$ exceeded the minimum precipitation threshold for vegetation growth in Bangkok, but the value of $1799 \mathrm{~mm}$ did not. Thus, the minimum precipitation threshold for vegetation growth in Bangkok is approximately 1900 mm (the blue dashed line in Figure 8a).

Insert Figure 8

\section{Discussion}

\subsection{MCD12Q1 dataset and CCI-LC dataset}

According to our results, the CCI-LC dataset had a higher accuracy than the MCD12Q1 dataset. The MCD12Q1 dataset showed higher commission errors in the classification of urban regions. More non-urban regions in the MCD12Q1 dataset than in CCI-LC dataset were classified as urban regions by mistake. Many studies have reported similar results. Cai et al. revealed that illogical transitions existed in the MCD12Q1 dataset for all consecutive years and were distributed 
most commonly in several regions all over the world (Cai, Liu, Sulla-Menashe, \& Friedl, 2014). Yang et al. compared and evaluated the accuracy of seven global land cover datasets over China, including the MCD12Q1 dataset, the CCI-LC dataset and other 5 datasets, and their results indicate that the CCI-LC dataset had the highest overall accuracy (Yang, Xiao, Feng, \& Li, 2017). Sharma et al. found that some forests were misclassified as non-forested areas in the MCD12Q1 dataset for Japan (Sharma, Hara, \& Tateishi, 2018). Sidhu pointed out that most barren areas were classified as urban areas or built up land in the MCD12Q1 dataset for Singapore (Sidhu, Pebesma, \& Wang, 2017).

\subsection{Synergies between climatic and anthropic factors}

Climate change and human activities have recently been recognized as the main causes of vegetation changes (Hansen et al., 2013; Herrmann, Anyamba, \& Tucker, 2005; L Xu et al., 2013). In urban environments, synergies between climatic and anthropic factors are common in vegetation growth. Our results indicate that the interannual fluctuation of urban vegetation change was likely related to the extreme climate events caused by the ENSO; however, the trend of urban vegetation change was mainly affected by land-use-related human activities. Many studies have stated that vegetation in cities that experience rapid urbanization was greatly affected by the negative impacts of urban sprawl (Jin, Wang, \& Li, 2018). The extreme climate events caused by ENSO also have significant impacts on vegetation growth (Erasmi, Propastin, Kappas, \& Panferov, 2009; Philippon, Martiny, Camberlin, Hoffman, \& Gond, 2014; Poveda \& Salazar, 2004). Their results were coincide with the current study.

\subsection{Urban environment and sustainability}

Vegetation accounts for the main part of terrestrial ecosystems and plays a key role in the flows of matter and energy among the pedosphere, hydrosphere and atmosphere, thus regulating the climate of the Earth (J. Chen et al., 2019; Hu, Fu, Liu, Jin, \& Guo, 2010; Peng et al., 2014; Piao, Fang, \& He, 2006). Urban green spaces not only provide urban residents with ideal arenas 
where they can rest, communicate and socially interact but also offer various kinds of ecosystem service functions (Liyan $\mathrm{Xu}, \mathrm{You}, \mathrm{Li}, \& \mathrm{Yu}, 2016$ ), such as regulating the climate system, decarbonizing the atmosphere via carbon sequestration, controlling air pollution control, reducing noise reduction and evaporative cooling processes that mitigate climate warming (Hong \& Guo, 2017; Prăvălie, 2018; You, 2016). Rapid urban expansion has led to a series of negative environmental consequences, such as air pollution (G. Xu et al., 2016), urban heat islands (Duncan et al., 2019; X. Li, Zhou, Asrar, Imhoff, \& Li, 2017) landscape fragmentation (Kowe, Mutanga, Odindi, \& Dube, 2020)and degradation of ecological services (J. Xu, Chen, \& Liu, 2020) in the BR region. The lack of green space is likely the major driver of the urban heat island effect (Duncan et al., 2019). Many studies have reported that the land surface temperature at city centers is higher than that in rural areas (Buyantuyev \& Wu, 2010; Keeratikasikorn \& Bonafoni, 2018; Khamchiangta \& Dhakal, 2019; Y. Liu, Peng, \& Wang, 2017). Decrease in forest area and increase in energy consumption which is caused by the accelerating urbanization in the BR region has led to serious air pollution dominated by $\mathrm{PM}_{2.5}$ (Fang et al., 2020). Land use change which is also caused by the urbanization in the BR region has directly influenced the distribution of ecosystem services by altering their intrinsic processes (J. Xu, Chen, Liu, \& Fan, 2020). According to the ecosystem service value per unit area, different land cover types are ranked from high to low as wetland, water body, forest, grassland, cropland, unused land (shrub and sparsely vegetated area) and built-up land (T. Li et al., 2010). Human interventions such as shifts in management practices are likely to have a major impact on vegetation growth and associated ecological processes (Suepa et al., 2016). In Shenzhen, the land cover dynamics showed two main characteristics. First, with rapid urbanization, new urban green spaces were also increasing. By 2016, Shenzhen had established 50 forest parks, 88 city parks and 758 community parks (Wu, Ye, Du, \& Luo, 2017). Land cover types with lower $P_{v}$ values and smaller ecosystem service values per unit area were replaced by forests. Moreover, recognizing the importance of forests in water conservation, the Shenzhen government has increased the forested area around water sources in recent years, which has had a positive influence on urban drinking water safety. Second, the $P_{v}$ values of original urban 
green spaces increased significantly as well. A consensus has emerged that impervious land cover, such as a large portion of built-up areas, leads to warming, and larger cities have greater surface urban heat island effects (H. Li et al., 2018). Increasing the area and $P_{v}$ values of urban green spaces not only has a cooling effect but also improves environmental quality and urban livability.

Changes in land cover types due to urbanization are likely to cause changes in ecological services and functions. If such changes are not considered during the policymaking process, the urban environment will be degraded. Sometimes, these degradations are difficult to reverse. Since the early 1990s, the Bangkok government has engaged in an active street tree-planting campaign; however, rough management has hindered the government's ability to improve Bangkok's green spaces and urban forest (Thaiutsa, Puangchit, Kjelgren, \& Arunpraparut, 2008). Rapid urbanization without adequate green spaces was the main characteristic of the land cover dynamics in Bangkok. Lacking green spaces, a city is fragile because rapid urbanization leads to the occupation of the natural environment (Wang, Chen, \& Kubota, 2016). However, the natural vegetation in wetlands, swamps and marshes was destroyed, which subsequently led to a decline of ecosystem service functions and environmental quality (Ali et al., 2018; Keeratikasikorn \& Bonafoni, 2018). Once the original vegetation is destroyed, it is difficult to restore it. Thus, urbanization under rough land management and a rash land development plan are unsustainable.

Urban green spaces are associated with the livability and sustainability of a city. However, they are usually ignored or underestimated by urban planning policymakers. As a result, urban green spaces are gradually being occupied by urban sprawl (Kong, Yin, \& Nakagoshi, 2007). Social development and vegetation greening can be either synergic or conflicting in landscape evolution (Y. Liu et al., 2019). The urbanization process does not necessarily result in large-scale vegetation degradation (D. Li, Wu, Liang, \& Li, 2020), especially when the demand for green space is carefully considered in the urbanization process. The win-win goal of sustainable development should consider both ecological conservation and social development. The green development pathway toward sustainable development goals also coincides with the core purpose of the BRI. 


\section{Conclusions}

As in a typical monsoon region, the vegetation in Bangkok and Shenzhen fluctuated with the extreme climate events caused by the ENSO. The major climate driving factors of vegetation growth in the two cities were different because Bangkok is hotter and Shenzhen is wetter. The vegetation of the two cities changed in opposite trends after 2005 due to the different urbanization strategies. Changes in land cover types always have a significant impact on the urban environment and sustainability. Rapid urbanization without enough green space leads to a degradation of the urban environment and livability. The green development pathway towards sustainable development goals is related to human well-being in the BR region, and this topic requires serious considerations of environmental quality and urban livability during the high-speed social development process.

\section{References}

Ali, G., Pumijumnong, N., \& Cui, S. (2018). Valuation and validation of carbon sources and sinks through land cover/use change analysis: The case of Bangkok metropolitan area. Land Use Policy, 70, 471-478. doi:https://doi.org/10.1016/j.landusepol.2017.11.003

Ascensão, F., Fahrig, L., Clevenger, A. P., Corlett, R. T., Jaeger, J. A., Laurance, W. F., \& Pereira, H. M. (2018). Environmental challenges for the Belt and Road Initiative. Nature Sustainability, 1(5), 206-209.

Buyantuyev, A., \& Wu, J. (2010). Urban heat islands and landscape heterogeneity: linking spatiotemporal variations in surface temperatures to land-cover and socioeconomic patterns. Landscape Ecology, 25(1), 17-33. doi:10.1007/s10980-009-9402-4

Cai, S., Liu, D., Sulla-Menashe, D., \& Friedl, M. A. (2014). Enhancing MODIS land cover product with a spatialtemporal modeling algorithm. Remote Sensing of Environment, 147, $243-255$. doi:https://doi.org/10.1016/j.rse.2014.03.012

Carlson, T. N., \& Ripley, D. A. (1997). On the relation between NDVI, fractional vegetation cover, and leaf area index. Remote Sensing of Environment, 62(3), 241-252. doi:https://doi.org/10.1016/S0034-4257(97)00104-1

Chen, J., Ju, W., Ciais, P., Viovy, N., Liu, R., Liu, Y., \& Lu, X. (2019). Vegetation structural change since 1981 significantly enhanced the terrestrial carbon sink. Nature Communications, 10, 7. doi:10.1038/s41467-019-12257-8

Chen, W. Y., \& Hu, F. Z. Y. (2015). Producing nature for public: Land-based urbanization and provision of public green spaces in China. Applied Geography, 58, 32-40. doi:https://doi.org/10.1016/j.apgeog.2015.01.007

Duncan, J., Boruff, B., Saunders, A., Sun, Q., Hurley, J., \& Amati, M. (2019). Turning down the heat: An enhanced understanding of the relationship between urban vegetation and surface temperature at the city scale. Science of the Total Environment, 656, 118-128.

Erasmi, S., Propastin, P., Kappas, M., \& Panferov, O. (2009). Spatial Patterns of NDVI Variation over Indonesia and Their Relationship to ENSO Warm Events during the Period 1982-2006. Journal of Climate, 22(24), 6612-6623. doi:10.1175/2009jcli2460.1 
Fang, K., Wang, T., He, J., Wang, T., Xie, X., Tang, Y., . . Xu, A. (2020). The distribution and drivers of PM2.5 in a rapidly urbanizing region: The Belt and Road Initiative in focus. Science of the Total Environment, 716, 137010. doi:https://doi.org/10.1016/j.scitotenv.2020.137010

Friedl, M. A., Sulla-Menashe, D., Tan, B., Schneider, A., Ramankutty, N., Sibley, A., \& Huang, X. (2010). MODIS Collection 5 global land cover: Algorithm refinements and characterization of new datasets. Remote Sensing of Environment, 114(1), 168-182. doi:https://doi.org/10.1016/j.rse.2009.08.016

Fu, B., Li, S., Yu, X., Yang, P., Yu, G., Feng, R., \& Zhuang, X. (2010). Chinese ecosystem research network: Progress and perspectives. Ecological Complexity, 7(2), 225-233. doi:10.1016/j.ecocom.2010.02.007

Ganguly, S., Friedl, M. A., Tan, B., Zhang, X., \& Verma, M. (2010). Land surface phenology from MODIS: Characterization of the Collection 5 global land cover dynamics product. Remote Sensing of Environment, 114(8), 1805-1816. doi:https://doi.org/10.1016/j.rse.2010.04.005

Hansen, M. C., Potapov, P. V., Moore, R., Hancher, M., Turubanova, S. A., Tyukavina, A., . . Loveland, T. R. (2013). High-resolution global maps of 21st-century forest cover change. Science, 342(6160), 850-853.

Herrmann, S. M., Anyamba, A., \& Tucker, C. J. (2005). Recent trends in vegetation dynamics in the African Sahel and their relationship to climate. Global Environmental Change, 15(4), 394-404.

Hong, W., \& Guo, R. (2017). Indicators for quantitative evaluation of the social services function of urban greenbelt systems: A case study of Shenzhen, China. Ecological Indicators, 75, $259-267$. doi:https://doi.org/10.1016/j.ecolind.2016.12.044

Hu, C., Fu, B., Liu, G., Jin, T., \& Guo, L. (2010). Vegetation patterns influence on soil microbial biomass and functional diversity in a hilly area of the Loess Plateau, China. Journal of Soils and Sediments, 10(6), 1082-1091. doi:10.1007/s11368-010-0209-3

Huang, B., Thorne, P. W., Banzon, V. F., Boyer, T., Chepurin, G., Lawrimore, J. H., . . Zhang, H.-M. (2017). Extended Reconstructed Sea Surface Temperature, Version 5 (ERSSTv5): Upgrades, Validations, and Intercomparisons. Journal of Climate, 30(20), 8179-8205. doi:10.1175/jcli-d-16-0836.1

Jin, K., Wang, F., \& Li, P. (2018). Responses of Vegetation Cover to Environmental Change in Large Cities of China. Sustainability, 10(1), 270.

Keeratikasikorn, C., \& Bonafoni, S. (2018). Satellite Images and Gaussian Parameterization for an Extensive Analysis of Urban Heat Islands in Thailand. Remote Sensing, 10(5), 665.

Kelly, M., Tuxen, K. A., \& Stralberg, D. (2011). Mapping changes to vegetation pattern in a restoring wetland: Finding pattern metrics that are consistent across spatial scale and time. Ecological Indicators, 11(2), $263-273$. doi:10.1016/j.ecolind.2010.05.003

Khamchiangta, D., \& Dhakal, S. (2019). Physical and non-physical factors driving urban heat island: Case of Bangkok Metropolitan Administration, Thailand. Journal of Environmental Management, 248, 109285. doi:https://doi.org/10.1016/j.jenvman.2019.109285

Kong, F., Yin, H., \& Nakagoshi, N. (2007). Using GIS and landscape metrics in the hedonic price modeling of the amenity value of urban green space: A case study in Jinan City, China. Landscape and Urban Planning, 79(3), 240-252. doi:https://doi.org/10.1016/j.landurbplan.2006.02.013

Kowe, P., Mutanga, O., Odindi, J., \& Dube, T. (2020). A quantitative framework for analysing long term spatial clustering and vegetation fragmentation in an urban landscape using multi-temporal landsat data. International Journal of Applied Earth Observation and Geoinformation, 88, 102057. doi:https://doi.org/10.1016/j.jag.2020.102057

Lechner, A. M., Chan, F. K. S., \& Campos-Arceiz, A. (2018). Biodiversity conservation should be a core value of China's Belt and Road Initiative. Nature Ecology E Evolution, 2(3), 408-409. doi:10.1038/s41559-017-0452-8

Li, D., Wu, S., Liang, Z., \& Li, S. (2020). The impacts of urbanization and climate change on urban vegetation dynamics in China. Urban Forestry E Urban Greening, 54, 126764. doi:https://doi.org/10.1016/j.ufug.2020.126764 
Li, H., Zhou, Y., Li, X., Meng, L., Wang, X., Wu, S., \& Sodoudi, S. (2018). A new method to quantify surface urban heat island intensity. Science of the Total Environment, 624, 262-272.

Li, T., Li, W., \& Qian, Z. (2010). Variations in ecosystem service value in response to land use changes in Shenzhen. Ecological Economics, 69(7), 1427-1435. doi:https://doi.org/10.1016/j.ecolecon.2008.05.018

Li, X., Zhou, Y., Asrar, G. R., Imhoff, M., \& Li, X. (2017). The surface urban heat island response to urban expansion: A panel analysis for the conterminous United States. Science of the Total Environment, 605-606, 426-435. doi:https://doi.org/10.1016/j.scitotenv.2017.06.229

Liu, H., Fang, C., Miao, Y., Ma, H., Zhang, Q., \& Zhou, Q. (2018). Spatio-temporal evolution of population and urbanization in the countries along the Belt and Road 1950-2050. Journal of Geographical Sciences, 28(7), 919936.

Liu, Y., Peng, J., \& Wang, Y. (2017). Diversification of land surface temperature change under urban landscape renewal: A case study in the main city of Shenzhen, China. Remote Sensing, 9(9), 919.

Liu, Y., Zhao, W., Hua, T., Wang, S., \& Fu, B. (2019). Slower vegetation greening faced faster social development on the landscape of the Belt and Road region. Science of the Total Environment, 697, 134103. doi:https://doi.org/10.1016/j.scitotenv.2019.134103

Peng, S., Piao, S., Zeng, Z., Ciais, P., Zhou, L., Li, L. Z. X., . . Zeng, H. (2014). Afforestation in China cools local land surface temperature. Proceedings of the National Academy of Sciences, 111(8), 2915-2919. doi:10.1073/pnas.1315126111

Permpool, N., Bonnet, S., \& Gheewala, S. H. (2016). Greenhouse gas emissions from land use change due to oil palm expansion in Thailand for biodiesel production. Journal of Cleaner Production, 134, 532-538.

Pettitt, A. (1979). A non-parametric approach to the change-point problem. Journal of the Royal Statistical Society: Series C (Applied Statistics), 28(2), 126-135.

Philippon, N., Martiny, N., Camberlin, P., Hoffman, M. T., \& Gond, V. (2014). Timing and Patterns of the ENSO Signal in Africa over the Last 30 Years: Insights from Normalized Difference Vegetation Index Data. Journal of Climate, 27(7), 2509-2532. doi:10.1175/jcli-d-13-00365.1

Piao, S., Fang, J., \& He, J. (2006). Variations in vegetation net primary production in the Qinghai-Xizang Plateau, China, from 1982 to 1999. Climatic Change, 74(1-3), 253-267. doi:10.1007/s10584-005-6339-8

Piao, S., Wang, X., Ciais, P., Zhu, B., Wang, T., \& Liu, J. (2011). Changes in satellite-derived vegetation growth trend in temperate and boreal Eurasia from 1982 to 2006. Global Change Biology, 17(10), 3228-3239. doi:10.1111/j.13652486.2011.02419.x

Poveda, G., \& Salazar, L. F. (2004). Annual and interannual (ENSO) variability of spatial scaling properties of a vegetation index (NDVI) in Amazonia. Remote Sensing of Environment, 93(3), $391-401$. doi:https://doi.org/10.1016/j.rse.2004.08.001

Prăvălie, R. (2018). Major perturbations in the Earth's forest ecosystems. Possible implications for global warming. Earth-Science Reviews, 185, 544-571. doi:https://doi.org/10.1016/j.earscirev.2018.06.010

Sharma, R. C., Hara, K., \& Tateishi, R. (2018). Developing Forest Cover Composites through a Combination of Landsat8 Optical and Sentinel-1 SAR Data for the Visualization and Extraction of Forested Areas. Journal of Imaging, 4(9), 105.

Sicard, P., Mangin, A., Hebel, P., \& Malléa, P. (2010). Detection and estimation trends linked to air quality and mortality on French Riviera over the 1990-2005 period. Science of the Total Environment, 408(8), 1943-1950.

Sidhu, N., Pebesma, E., \& Wang, Y.-C. (2017). Usability Study to Assess the IGBP Land Cover Classification for Singapore. Remote Sensing, 9(10), 1075.

Song, Y., Jin, L., \& Wang, H. (2018). Vegetation changes along the Qinghai-Tibet Plateau engineering corridor since 2000 induced by climate change and human activities. Remote Sensing, 10(1), 95. 
Stow, D., Daeschner, S., Hope, A., Douglas, D., Petersen, A., Myneni, R., . . Oechel, W. (2003). Variability of the Seasonally Integrated Normalized Difference Vegetation Index Across the North Slope of Alaska in the 1990s. International Journal of Remote Sensing, 24(5), 1111-1117. doi:10.1080/0143116021000020144

Suepa, T., Qi, J., Lawawirojwong, S., \& Messina, J. P. (2016). Understanding spatio-temporal variation of vegetation phenology and rainfall seasonality in the monsoon Southeast Asia. Environmental research, 147, 621-629.

Tan, L., Shen, C.-C., Löwemark, L., Chawchai, S., Edwards, R. L., Cai, Y., . . Wohlfarth, B. (2019). Rainfall variations in central Indo-Pacific over the past 2,700 y. Proceedings of the National Academy of Sciences, 116(35), 17201-17206. doi:10.1073/pnas.1903167116

Thaiutsa, B., Puangchit, L., Kjelgren, R., \& Arunpraparut, W. (2008). Urban green space, street tree and heritage large tree assessment in Bangkok, Thailand. Urban Forestry \& Urban Greening, 7(3), 219-229. doi:https://doi.org/10.1016/j.ufug.2008.03.002

Wang, Y., Chen, L., \& Kubota, J. (2016). The relationship between urbanization, energy use and carbon emissions: evidence from a panel of Association of Southeast Asian Nations (ASEAN) countries. Journal of Cleaner Production, 112, 1368-1374. doi:https://doi.org/10.1016/j.jclepro.2015.06.041

Wu, C., Ye, X., Du, Q., \& Luo, P. (2017). Spatial effects of accessibility to parks on housing prices in Shenzhen, China. Habitat International, 63, 45-54. doi:https://doi.org/10.1016/j.habitatint.2017.03.010

Xu, G., Jiao, L., Zhao, S., Yuan, M., Li, X., Han, Y., . . . Dong, T. (2016). Examining the Impacts of Land Use on Air Quality from a Spatio-Temporal Perspective in Wuhan, China. Atmosphere, 7(5), 62.

Xu, J., Chen, J., \& Liu, Y. (2020). Partitioned responses of ecosystem services and their tradeoffs to human activities in the Belt and Road region. Journal of Cleaner Production, 276, 123205. doi:https://doi.org/10.1016/j.jclepro.2020.123205

Xu, J., Chen, J., Liu, Y., \& Fan, F. (2020). Identification of the geographical factors influencing the relationships between ecosystem services in the Belt and Road region from 2010 to 2030. Journal of Cleaner Production, 124153. doi:https://doi.org/10.1016/j.jclepro.2020.124153

Xu, L., Myneni, R., Chapin Iii, F., Callaghan, T. V., Pinzon, J., Tucker, C. J., . . Tømmervik, H. (2013). Temperature and vegetation seasonality diminishment over northern lands. Nature Climate Change, 3(6), 581-586.

Xu, L., You, H., Li, D., \& Yu, K. (2016). Urban green spaces, their spatial pattern, and ecosystem service value: The case of Beijing. Habitat International, 56, 84-95. doi:https://doi.org/10.1016/j.habitatint.2016.04.005

Yang, Y., Xiao, P., Feng, X., \& Li, H. (2017). Accuracy assessment of seven global land cover datasets over China. ISPRS Journal of Photogrammetry and Remote Sensing, 125, 156-173. doi:https://doi.org/10.1016/j.isprsjprs.2017.01.016

You, H. (2016). Characterizing the inequalities in urban public green space provision in Shenzhen, China. Habitat International, 56, 176-180. doi:https://doi.org/10.1016/j.habitatint.2016.05.006

Zhang, B., He, C., Burnham, M., \& Zhang, L. (2016). Evaluating the coupling effects of climate aridity and vegetation restoration on soil erosion over the Loess Plateau in China. Science of the Total Environment, 539, 436-449.

Zhao, J., Chen, S., Jiang, B., Ren, Y., Wang, H., Vause, J., \& Yu, H. (2013). Temporal trend of green space coverage in China and its relationship with urbanization over the last two decades. Science of the Total Environment, 442, 455-465. doi:https://doi.org/10.1016/j.scitotenv.2012.10.014 


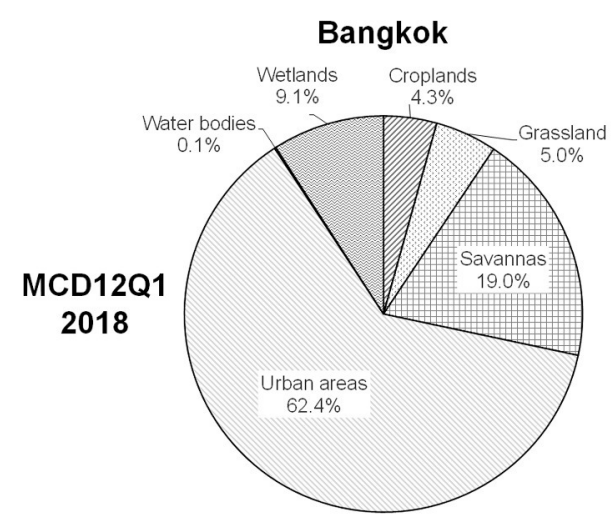

(a)

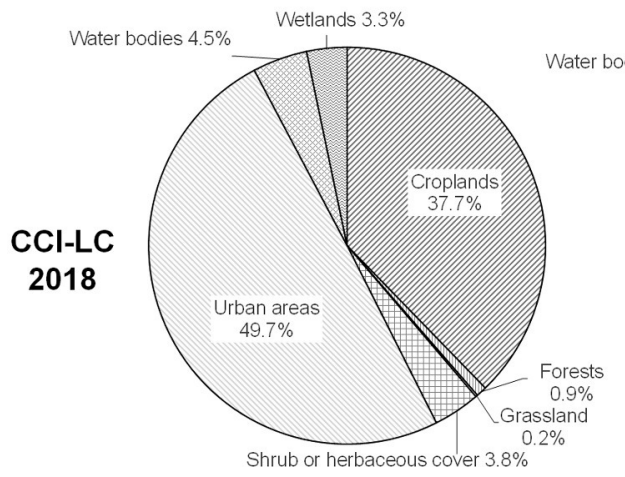

(c)

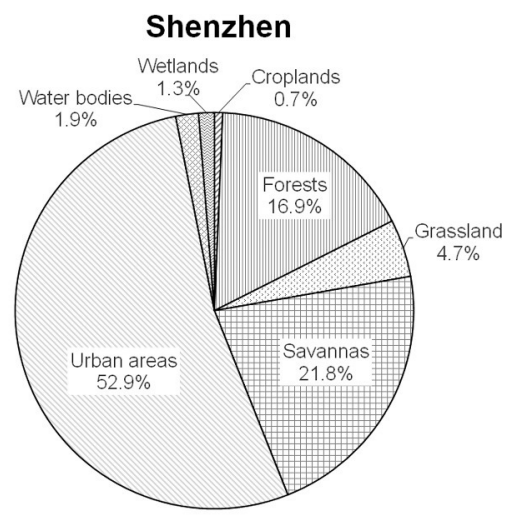

(b)

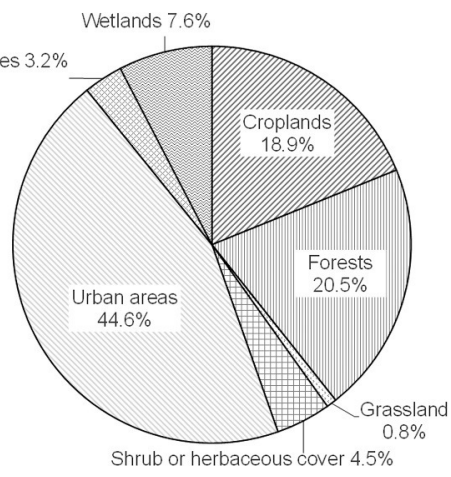

(d)

ldr_3788_figure 1.eps

This article is protected by copyright. All rights reserved. 


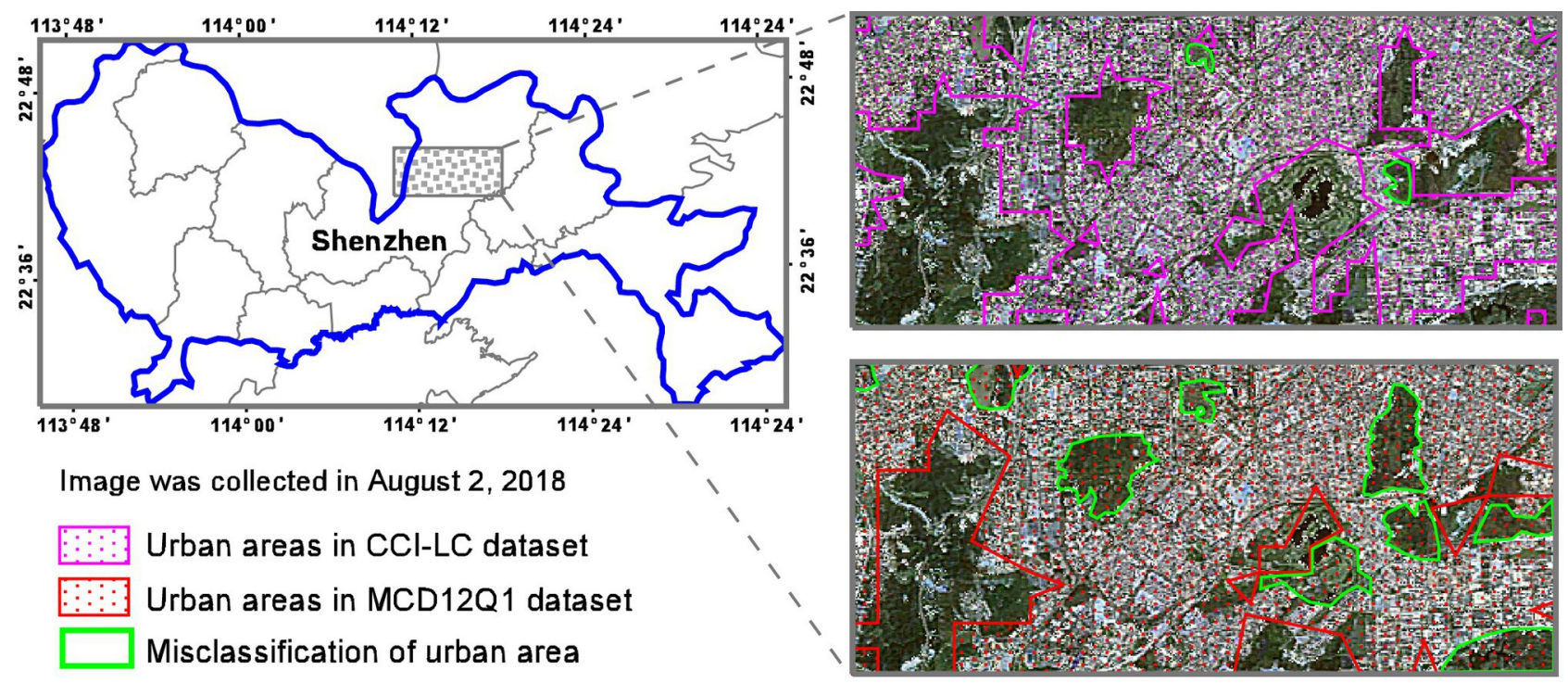

ldr_3788_figure 2.eps

This article is protected by copyright. All rights reserved. 
(a)

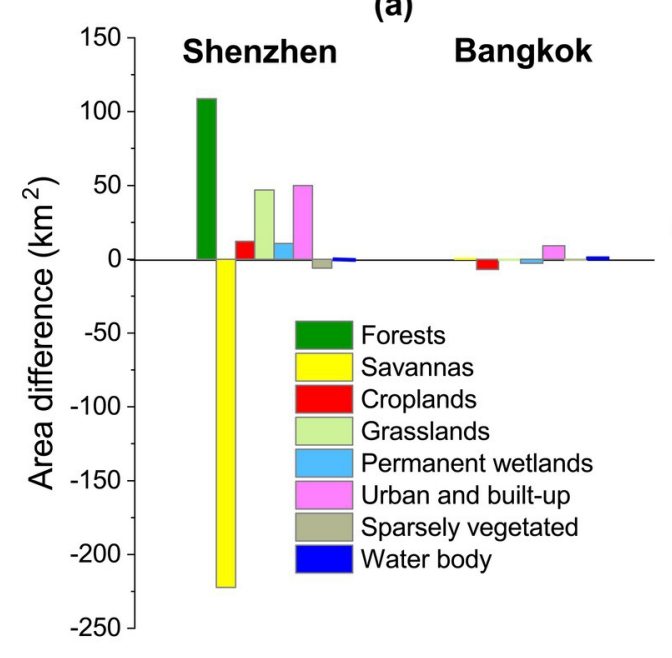

(b)
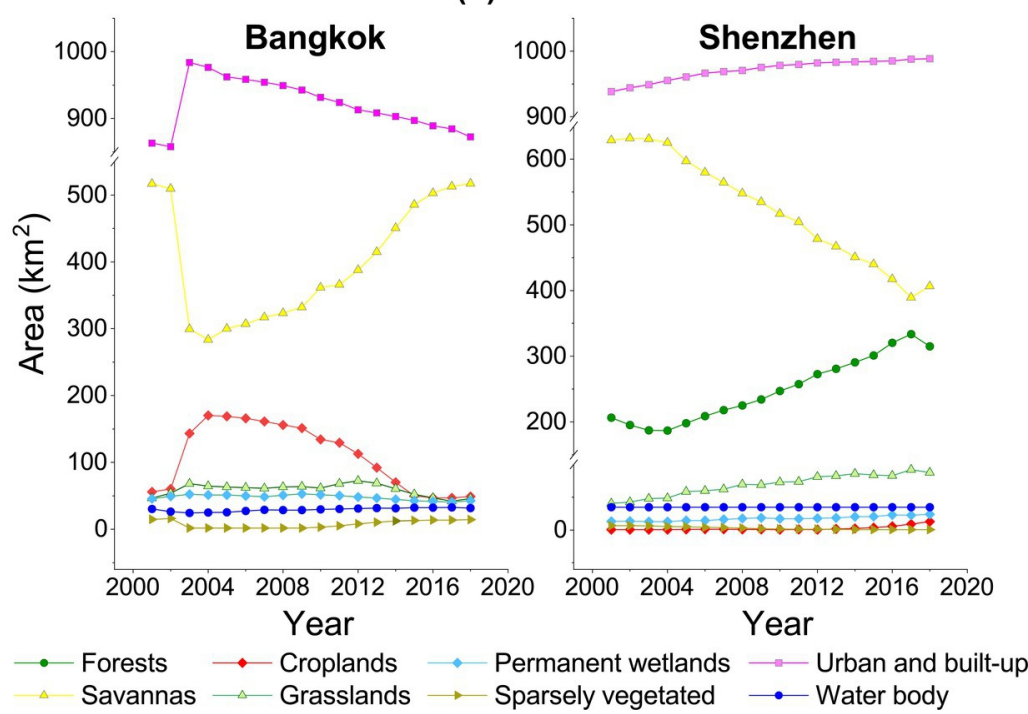

ldr_3788_figure 3.eps 


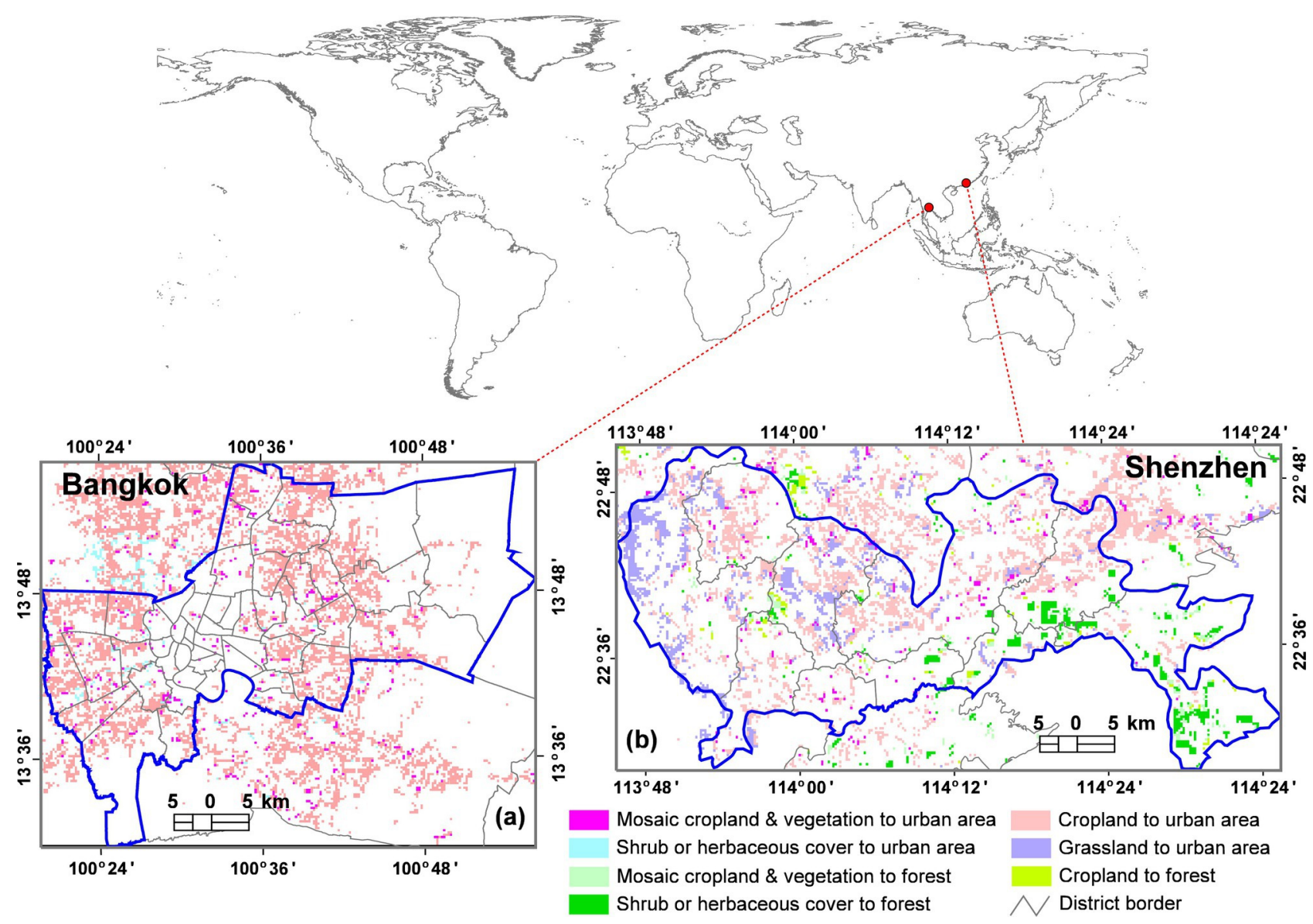

ldr_3788_figure 4.eps

This article is protected by copyright. All rights reserved. 

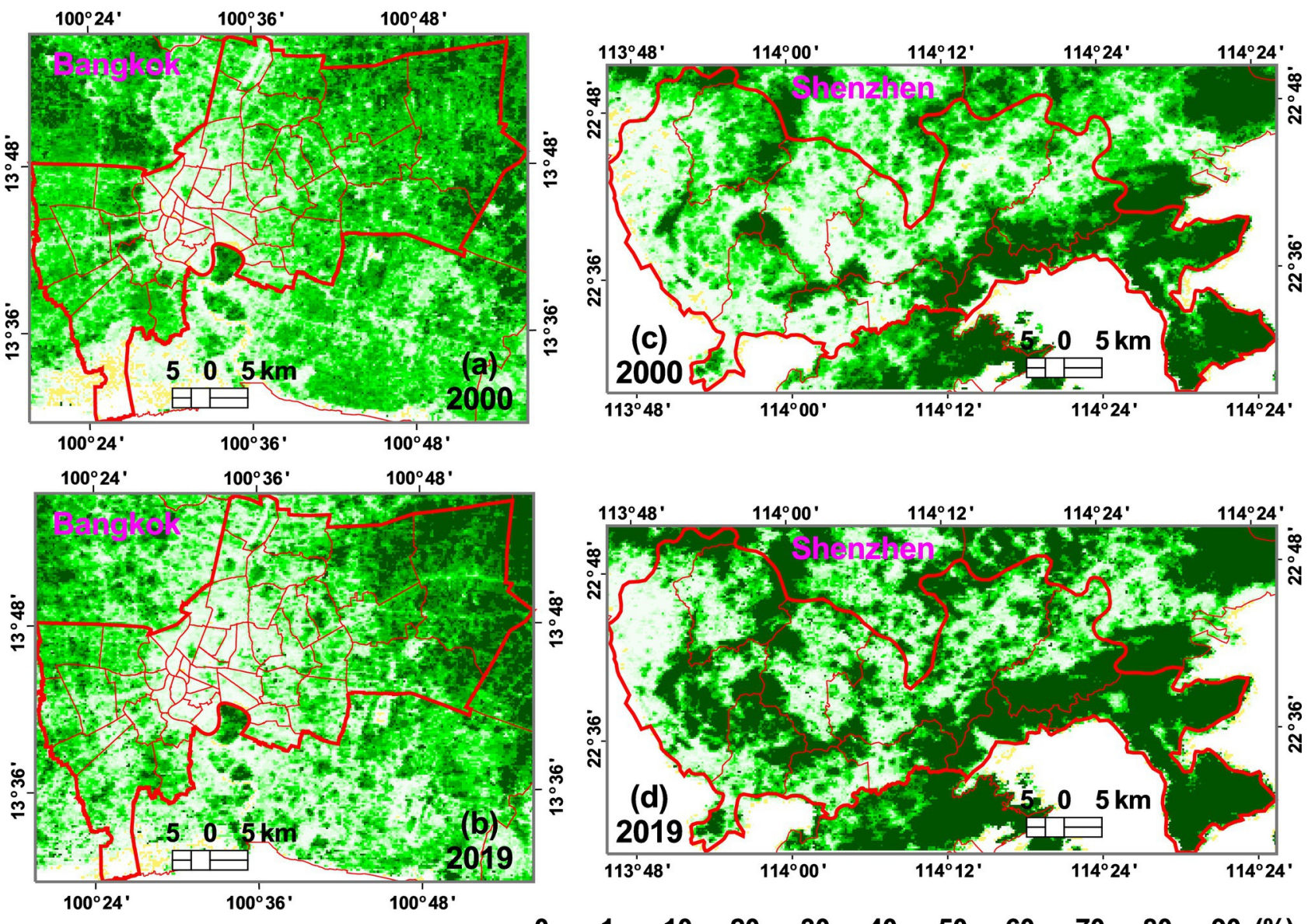

$\checkmark$ District border Vegetation coverage:

$\begin{array}{llllllllllll}0 & 1 & 10 & 20 & 30 & 40 & 50 & 60 & 70 & 80 & 90 & (\%)\end{array}$

ldr_3788_figure 5.eps

This article is protected by copyright. All rights reserved. 


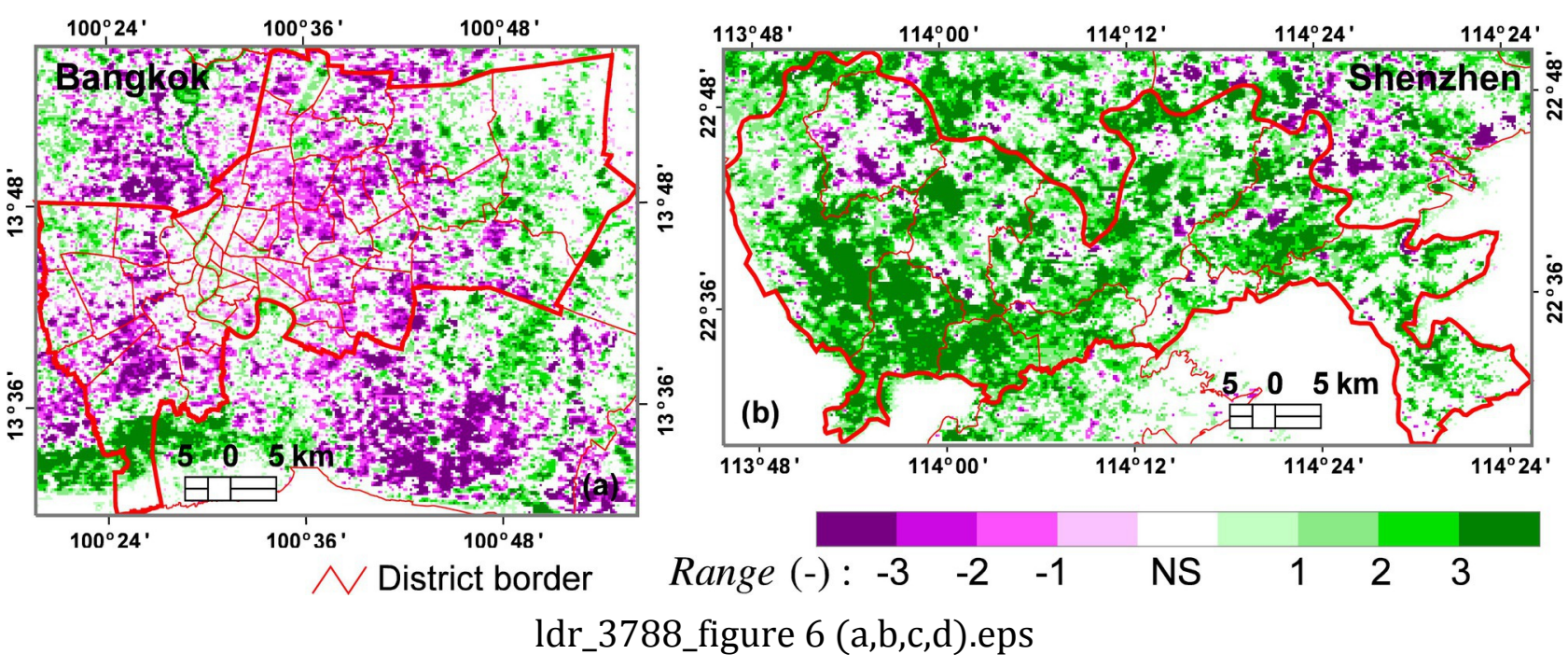

This article is protected by copyright. All rights reserved. 


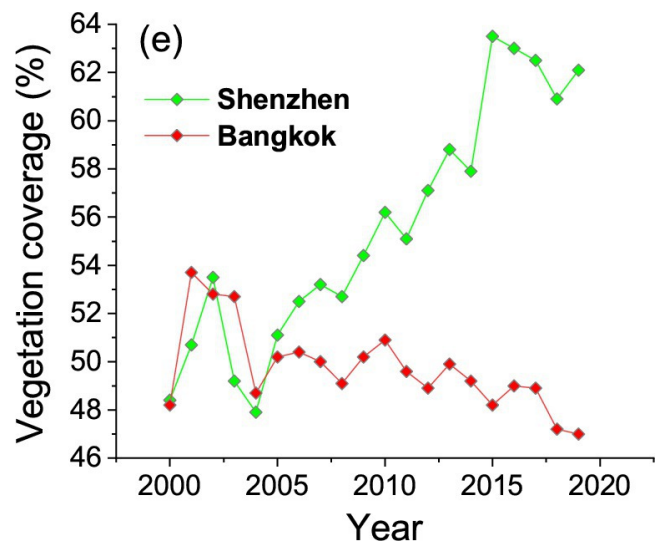

ldr_3788_figure 6 (e).eps

This article is protected by copyright. All rights reserved. 

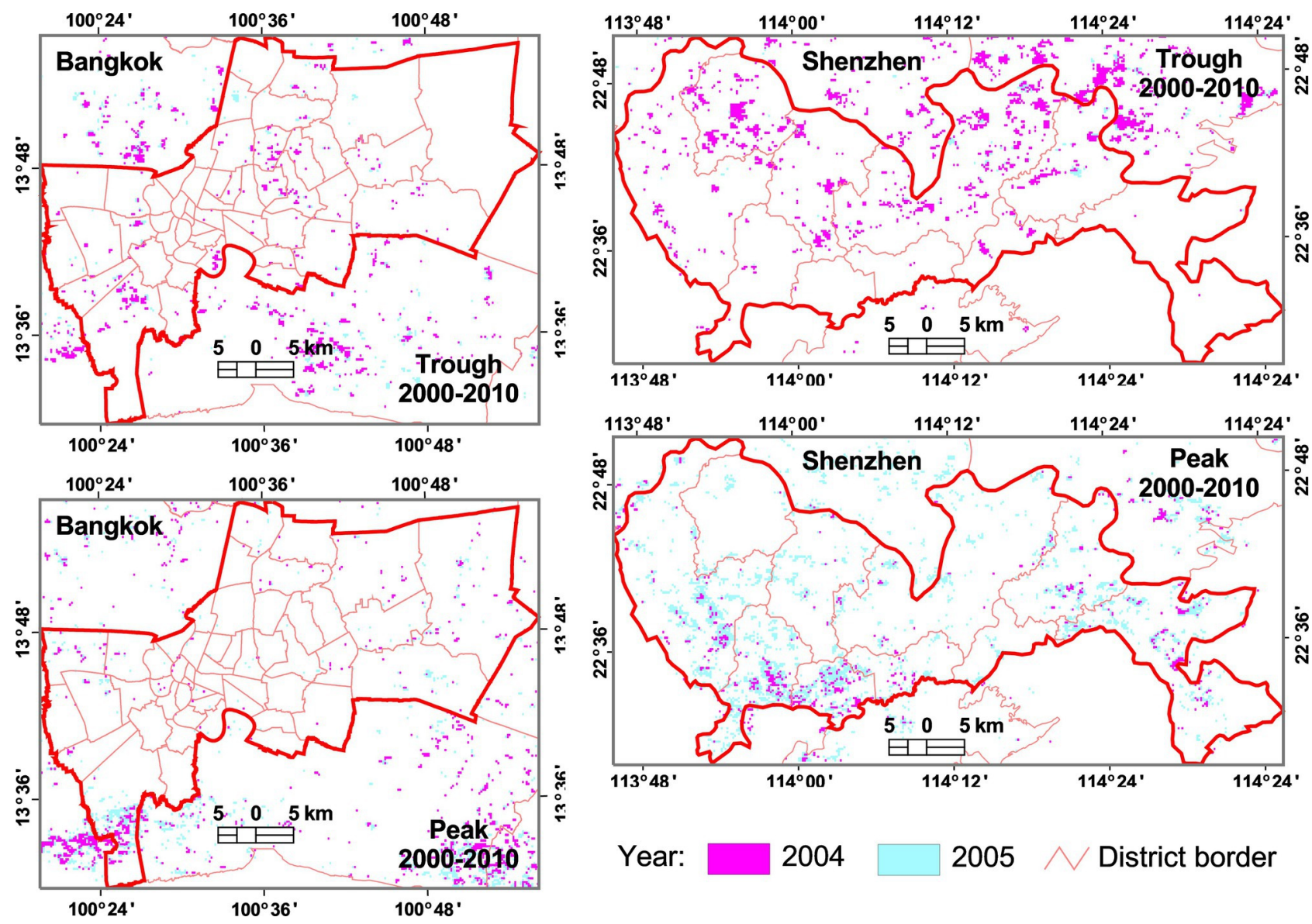

Year:

2004

2005

District border

ldr_3788_figure 7.eps 

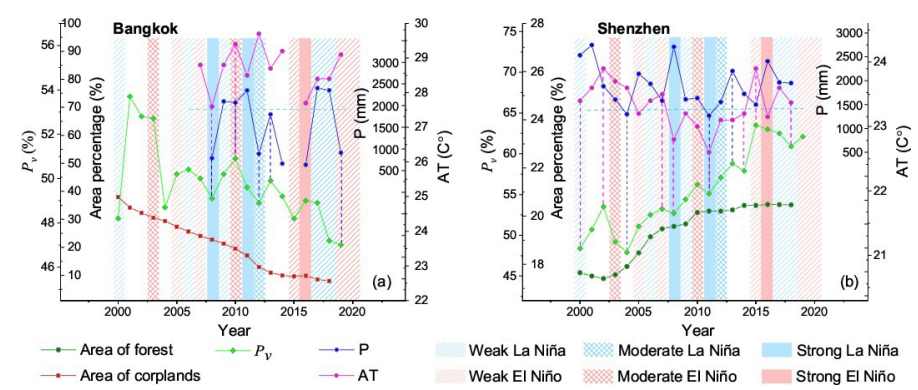

ldr_3788_figure 8.eps

This article is protected by copyright. All rights reserved. 
Table 1. Percentage (\%) of significant changes for two cities at a confidence level of 0.05 .

\begin{tabular}{cccc}
\hline City & $\begin{array}{c}\text { Significant } \\
\text { increase (\%) }\end{array}$ & $\begin{array}{c}\text { Significant } \\
\text { decrease (\%) }\end{array}$ & $\begin{array}{c}\text { Nonsignificant } \\
\text { change (\%) }\end{array}$ \\
\hline Bangkok & 16 & 33 & 51 \\
Shenzhen & 56 & 4 & 40 \\
\hline
\end{tabular}

This article is protected by copyright. All rights reserved. 


\section{University Library}

\section{- M M N E R VA A gateway to Melbourne's research publications}

Minerva Access is the Institutional Repository of The University of Melbourne

Author/s:

Song, Y;Aryal, J;Tan, L;Jin, L;Gao, Z;Wang, Y

Title:

Comparison of changes in vegetation and land cover types between Shenzhen and Bangkok

Date:

2021-02-02

Citation:

Song, Y., Aryal, J., Tan, L., Jin, L., Gao, Z. \& Wang, Y. (2021). Comparison of changes in vegetation and land cover types between Shenzhen and Bangkok. Land Degradation \& Development, 32 (3), pp.1192-1204. https://doi.org/10.1002/ldr.3788.

Persistent Link:

http://hdl.handle.net/11343/276392 